\title{
OCCUPATIONAL HAZARDS IN MINING AND MANUFACTURING SECTOR: AN ANALYSIS ON DISEASE CLAIMS IN MALAYSIA
}

\author{
Che Thalbi Md. Ismail *
}

\begin{abstract}
This paper examines the law regulating occupational illnesses or diseases suffered by workers at the work place. Its main focus is on the claims by workers to SOCSO for illness suffered or diseases contracted whilst performing their work or in the course of their employment. The main statute for compensation claim is Employees Social Security Act 1969 and the discussion will be made on the problem arising under section 28(1) and 28(4) of the 1969 Act. The issue involved is in establishing whether a correlation exists between the disease and the work performed by the workers. Such an issue could be the hindrance towards the success of such workers' claims. Hence, this paper will explore the issue by analyzing statistics and decided court cases. The analysis of the court cases revealed that most of the claims were turned down when the claimants failed to show that the injury or death were the result of the employment. The author also suggests an alternative to have a scheduled and monitored occupational health check-up on the workers' health to ensure whether any health problems occurs is due to the work.
\end{abstract}

\section{Introduction}

A worker is susceptible to all the health problems likely to be seen among members of the general community. However, the working population is exposed to health hazards over and above the rest of the community because of work practices, thereby providing another reason for special concern for their health. Hence, this paper in the first instance is to identify the hazards in the work place and the number of disease claims ${ }^{1}$ made by the workers. The analysis is made on the claims in manufacturing sector here because it is the

\footnotetext{
Senior Lecturer, School of Law (COLGIS), Universiti Utara Malaysia

'occupational diseases' here are those diseases listed under the Fifth Schedule of the Employees Social Security Act 1969.
} 
biggest sector in Malaysia. The mining sector is explained in the following part of this paper, as among the most hazardous sector. An analysis is made to the claim statistics made by the workers in these two sectors to see the ratio between successful and unsuccessful claims. Then, this paper analyses the reasons for the unsuccessful claims through the court cases. Next, based on the analysis of cases, it was found that in most of the claims, the workers failed to prove the element of 'in the course of employment'. Hence, the paper seeks the rational whether to persuade the decision-makers of the need to provide occupational health services through primary health care or other type of intervention strategy.

\section{Occupational Hazards in Mining and Manufacturing Sectors}

A worker is likely to suffer occupational diseases, as well as what are termed 'word-related diseases'. Every sector has it own work risks and hazards depending the used materials and the ergonomic factor (the surrounding of the work place and the way how work is carried out). The occurrence of an occupational disease also depends much on the working hours of a worker. Longer working hours will increase the risks of a disease. There is always a direct causal relationship between work hazards which are in excess of tolerable limits and the disease process. The World Health Organisation (WHO) identifies the following as characteristics of occupational disease: ${ }^{2}$

(a) factors in the work environment are predominant and essential in the causation of occupational diseases, e.g. silica dust and silicosis, lead fumes and lead poisoning, but other factors may nevertheless play a varying role in their occurrence. For example, individual susceptibility and age play a role in noise-induced hearing loss. Likewise, the presence of pulmonary tuberculosis among workers exposed to silica dust increases the extent and severity of silicosis.

\footnotetext{
2 WHO (World Health Organisation). Report of a WHO Expert Committee on Environmental and Health Monitoring in Occupational Health, 1973, WHO Technical Report Series, No.535, WHO, Geneva.
} 
(b) occupational diseases, by definition, exclusively affect working people exposed to the specific hazards in question. In some instances, however, manifestations of such diseases may also prevail elsewhere in the community. For example, in the case of endemic byssinosis $^{3}$ in an Egyptian village, workers processed flax in their homes, and the resulting dust exposure affected their wives and children. ${ }^{4}$ Work-sites may be situated in family dwellings, posing hazards to the other family members.

Hence, in this paper we shall see the hazards faced in the manufacturing and mining sector and how these hazards affect the health of the workers. According to the characteristics identified above, the hazards might not be the sole cause or the original factor of a disease. Some diseases might have developed before commencing the work. However, claims for these diseases can still be made if it can be proved that the work factor has aggravated the diseases materially.

\section{Hazards in Mining ${ }^{5}$ Sector}

In mining sector, noise-induced hearing loss is a common health problem due to the machines and vehicles operation. While, acute lung injury can be resulted from another hazard i.e. inhalation of dust (especially mineral dust) and various gases. ${ }^{6}$

In addition to the above hazard, respiratory disorder also could happen due to inhalation of the above materials and the symptoms of

\footnotetext{
3 Byssinosis is also called "brown lung", is an occupational lung disease caused by exposure to cotton dust in inadequately ventilated working environments. It commonly occurs in workers who are employed in yarn and fabric manufacture industries. Brown lung can ultimately result in narrowing of the trachea in the lungs, destruction of lung tissue and death from infection or respiratory failure. A kind of lung disease affecting the respiratory system of a person through inhalation of dust. See http://en.wikipedia.org/wiki/Byssinosis

4 El Batawi, M.A., Schilling, RSF and Valic F., "Byssinosis in the Egyptian cotton industry; changes in ventilatory capacity during the day"(1964) Br. J. Ind. Med., 21, 13-19.

5 Mining sector here will include quarries.

6 Jeyaratnam, J., Occupational Health in Developing Countries, (Oxford University Press: New York, 1992) p 76.
} 
asthma developed. In some cases, there was no temporal relationship between the symptoms and any particular incident or exposure due to the insidious onset and long latent period of the disease. Sometimes, a worker started to have symptoms after ceasing exposure to the dust $^{7}$ for years.

Another hazard in mining sector is the heavy work force carried out by workers. Any manual work done e.g. manual lifting of boxes or machines will cause musculoskeletal problems to workers. The work force also can aggravate any existing bad health condition such as hyper tension, hernia or back pain.

\section{Hazards in Manufacturing Sector}

Similarly in manufacturing sector, noise-induced hearing loss is a common health problem due to the machines operation. However, not all sections will expose the workers to this hazard. Dermatitis, ${ }^{8}$ is the next health problem due to the use of harmful agents or chemical. The type of chemicals used in the sector will depend on the type of product of the company.

The ergonomic factor of a work place does very much affect the health of workers. There are many types working conditions which are not healthy such as dust from the processed products, awkward working posture, long hours of work, vibration and the temperature of the working place.

Thus, repetitive strain injuries (RSI) is a typical kind of musculoskeletal problems among workers who handle work manually in this sector. Factors contributing to the development of $\mathrm{RSI}^{9}$ include the following:

7 This usually happen in the case of exposure to asbestos, silica, tar, coal. See Ng T.P., "Occupational Lung Diseases- Mineral Dusts" in Jeyaratnam J., Occupational Health in Developing Countries, 1992, Chap. 13 passim.

8 Dermatitis is a blanket term meaning any "inflammation of the skin" (e.g. rashes, etc.). There are several different types of dermatitis. The different kinds usually have in common an allergic reaction to specific allergens. The term may be used to refer to eczema, which is also known as dermatitis eczema or eczematous dermatitis. See http://en.wikipedia.org/ wiki/dermatitis.

9 Koh, Kee Seng \& Jeyaratnam, Occupational Medicine Practice, $2^{\text {nd }}$ ed., (Singapore: World Scientific Publishing Co. Pte. Ltd, 2001), p.241. 
(a) highly repetitive work

(b) work demanding a certain amount of force, exerting force on the arm;

(c) awkward posture during the execution of certain tasks;

(d) insufficient rest or recovery time leading to fatigue; and

(e) the ageing workforce with less resilience to wear and tear..

Workers from work sites which included electronics, sewing, appliance, bearing fabrication, bearing assembly and investment molding plants are among are highly at risk of this hazard. ${ }^{10}$

A survey was carried out by the Department of Occupational Safety and Health, Ministry of Human Resource (DOSH), ${ }^{11}$ found that the ergonomic hazards are very common to manufacturing workers. Among the hazardous work are manual lifting, awkward posture, forceful movement and the work load. The indoor climate in some factories also was not satisfactory. The hot and humid work stations can cause excessive fatigue and further, result in other potential health risks.

It is important to note that there are many other kinds of hazards that will lead to the occurrence of disease. As a result the hazards mentioned above are not exhaustive and hence, the workers in these two sectors are exposed to many other kinds of diseases.

\section{Occupational Disease Claims}

The number of workers according to the sector needs to be compared with the incidents in order to analyse the disease frequency. The statistic of workers registered with $\mathrm{SOCSO}^{12}$ will be explained through the following table:-

Ibid., p 242.

11 Mohtar Musri, Abu Bakar Che Man et. all, "Ergonomic Hazards of Small and MediumSized Industries in Malaysia" in Rampal KG, Hong L.K and Jagdev Singh (editors) Occupational Health in Asia, Proceedings of the $15^{\text {th }}$ Asian Conference on Occupational Health, 1997, Kuala Lumpur.

12 The statistic on the number of workers was gathered from SOCSO because due to section 5 ESSA 1969, all private workers have to be registered and insured according to the Act. 
Table 1

Number of Workers Registered With SOCSO ${ }^{13}$

\begin{tabular}{lccc}
\hline \multicolumn{1}{c}{ Type of industry } & 2009 & 2010 & 2011 \\
\hline A. Mining \& Quarries & & & \\
$\begin{array}{l}\text { Mining of coals, petroleum } \\
\text { Gas/ Metals, Salt, Other mining }\end{array}$ & 81750 & 86465 & 91583 \\
\hline
\end{tabular}

B. Manufacturing of -

Food/drinks, beverage, leather/ $\quad 898,347 \quad 950165 \quad 1,006,416$ textile, wood product/furniture

Paper and printing

Chemical compound (fertilizer, paint, soap, tyres etc)

Non-metallic mineral industry

Metal, machinery and equipment

Electricity, gas and steam

Other manufacturing industries

From the table, the number of workers is increasing every year in both sectors. The number of workers in mining industry range from 81,750 to 91,600 (from 2009-2011), while the workers registered in manufacturing sector are from $900,000-1,006,500$ in the same years. Manufacturing sector is the biggest sector and the workers are about 30 per cent from the total number of workers in Malaysia.

The number of disease incidents in both sectors is illustrated in the table below:

13 The statistic was collected from the SOCSO's Annual Report 2001 - 2006 
Table 2

Number of Diseases According to Sector Reported in $2010^{14}$

\begin{tabular}{lcc}
\hline \multicolumn{1}{c}{ Types of Diseases } & Manufacturing & Mining \\
\hline Asthma & 21 & \\
Tubercolusis & 20 & \\
Silicosis & 12 & \\
OLD & 16 & \\
(lung diseases) & & \\
Dermatitis & 180 & 3 \\
NIHL & 193 & \\
Musculo Diseases & 112 & \\
Psycososial (Stress) & & \\
Poisoning & 203 & \\
Biological Hepatitis & & \\
Other Biological & 2 & \\
Diseases & & \\
Cancer & 2 & \\
Other Diseases & 19 & \\
Other Non- & 26 & \\
Occupational Diseases & & \\
Total & 806 & \\
\hline
\end{tabular}

According to the statistic above, there are 780 cases (excluding 26 cases of non-occupational diseases) of various types of occupational diseases in manufacturing sector in 2010. This number is only 0.082 per cent out of the total number of the workers in manufacturing sector. The ratio of the disease incidences and the total workers is $1: 1218$. Whereas in mining sector, only 11 cases of occupational diseases reported in 2010 and this means the ratio of disease incidence compared to the nu mber of worker is 1:7860.

This means that the probability for a disease to occur in mining sector is very much lower than the one in manufacturing sector. Although the literature shows that the mining sector exposes workers

14 The data was gathered from the Dept. of Occupational Health and Safety (DOSH), Ministry of Human Resource. 
to so many kinds of dust, excessive noise and other non-healthy ergonomic factors, the number of disease incident is still very low. There is also no case of lung diseases reported in mining sector.

Another point to ponder here is that the number of claims for occupational diseases is very much lower than the claim for accidents. The accident claims in 2009 are about 90,000 compared to just 1800 disease cases. Hence, the later part of this paper will look at the deterrence in disease claims.

\section{Proving Work Place Hazards as the Cause of Disease}

In order to have a successful compensation claim, a worker must first prove that the disease was caused by the occupation and not anything else. In a tort claim, a worker must show the liability of the employer in ensuring a safe and healthy work place. The proof of employer's liability and its breach is not an easy task because disease is not an immediate effect of the employer's negligence. Some diseases show the symptoms after years of process. This is where the difference between 'accident' and 'disease' lies. There are some provisions affecting the direct liability of employers which must be shown by employees in their claims;

Section 10 of Factories and Machinery Act 1967,

Without prejudice to any law with respect to local authorities, in respect of any factory, the following provisions relating to safety shall apply:

(a) foundations and floors shall be of sufficient strength to sustain the loads for which they are designed; and no foundation or floor shall be overloaded;

(b) roofs shall be of sufficient strength to carry where necessary suspended loads;

(c) all floors, working levels, platforms, decks, stairways, passages, gangways, ladders and steps shall be of safe construction so as to prevent a 
risk of persons falling, and structurally sound so as to prevent a risk of collapse, and shall be properly maintained and kept, as far as reasonably practicable, free from any loose material and in a non-slippery condition;

(d) such means as are reasonably practicable shall be provided, maintained, and used so as to ensure safe access to any place at which any person has at any time to work;

(e) every opening, sump, pit or fixed vessel in a floor, or working level shall be securely covered or securely fenced so as to prevent risk of persons falling; and

(f) all goods, articles and substances which are stored or stacked shall be so placed or stacked--

(i) in such manner as will best ensure stability and prevent any collapse of the goods, articles or substances or their supports; and

(ii) in such a manner as not to interfere with the adequate distribution of light, adequate ventilation, proper operation of machinery, the unobstructed use of passageways or gangways and the efficient functioning or use of fire-fighting equipment.

Section 11 of the Factories and Machinery Act 1967

In every factory in which persons are exposed to risk of bodily injury from explosive, inflammable, poisonous or corrosive substances or ionising radiations, such measures as may be prescribed shall be taken as will eliminate the risk.

Section 15(1) of the Occupational Safety and Health Act 1994 (OSHA 1994) 
It shall be the duty of every employer to ensure, so far as is practicable, the safety, health and welfare at work of all his employees. The matters to which the duty extends include maintenance of plant and systems of work, use or operation, handling, storage and transport of plant and substances, information, instruction, training and supervision as is necessary, maintenance of a working environment and etc. (listed down under s.15(1)(a)-(e)).

Section 24 of the Occupational Safety and Health Act 1994 provides on the duty of employees to take reasonable care for the safety and health of himself and of other persons who may be affected by his acts, to co-operate with his employer, to wear and use at all times any protective equipment or clothing and to comply with any instruction on occupational safety and health instituted by his employer. Hence, if a worker fails to perform his duty, the compensation will be reduced due to his own contributory negligence.

A compensation claim made under Employees Social Security Act 1969 (ESSA 1969) however, does not burden workers with the duty of proving the employer's breach of duties. Section 28(4) of the ESSA 1969 requires a worker to prove that the disease 'arise out of or in the course of employment'. While section 28(1) provides that if an employee who is employed in any occupation described in the Fifth Schedule ${ }^{15}$ contracts any disease or injury shown in the said Schedule to be related to that occupation, or if an employee who has been employed in such occupation contracts such a disease or injury within sixty months after ceasing to be so employed, the contracting of the disease or injury shall, unless the contrary is proved, be deemed to be an employment injury arising out of and in the course of employment

Whether workers are having problem in claiming damages or compensation due to the difficulty in showing the causation link between diseases and the occupation? It shall be illustrated through the following cases.

$5^{\text {th }}$ Schedule of the ESSA 1969 states a list of diseases recognized by the Act. 


\section{Analysis of Court Cases}

There are only a few tort cases affecting the claim of workers in occupational diseases. This is probably due to the compensation scheme provided under the ESSA 1969. Among the cases are:

First, in the case of Kuppusamy v Golden Hope Rubber Estate Ltd, ${ }^{16}$ (Federal Court Kuala Lumpur), the appellant was a general worker in charge of cleaning the respondent's plantation. After attending a daily 'muster' of work people, she returned home to collect some tools without obtaining permission of anyone in a supervisory capacity. At home, she fell down and sustained injuries (in her womb) from which she died. The High Court set aside the award granted by the arbitrator to her family based on the reason that at the time she fell, the employment had not commenced yet and not in the course of the employment.

Her family made an appeal to the Federal Court and the judges unanimously held that the death must be deemed to be arisen out of and in the course of employment. Even though the worked had not been commenced yet, the worker returned in order to fetch the tools and further, perform her job. The purpose of the return was considered as a part of the employment even she had not obtained anyone's permission.

The next explanation for disease claim was given in the case of Persin Kaur v The Renong Tin Mine Dredging ${ }^{17}$. Here, a 'watchman' who was employed in the respondent's mining died while on his way to a wash room. He fell down and complained of the pain in his chest. His widow claimed for compensation under the Workmen's Compensation Ordinance 1952. The High Court rejected her claim on the ground that the death was not attributed to his occupation. She further appealed to the Federal Court.

The appellant here contended that the husband's death arose out of employment because the death occurred during the working

[1965] 1 MLJ 178

[1967] 2 MLJ 286 
hours i.e. from $11 \mathrm{pm}-8.00 \mathrm{am}^{18}$. Nevertheless, the court held that the contention was successfully denied by the employer when presenting expert evidence showing that the death was due to the natural cause not contributed by his employment. The evidence by the doctor proved that a person attaining that age (54 years) would normally get the heart disease even without prior symptoms. The expert view was accepted even in the absence of post-mortem test carried out on the deceased.

Further, the case of Gan Poh v. Union Ominbus Co Ltd. ${ }^{19}$ involved a claimant employed as a bus-conductor in the respondent's company. Among his duties were managing the tickets, passengers and their luggage. He safeguarded the passengers' safety and loading/ unloading their bags from the roof part of the bus. The employee applied for sick leave on April 9, 1965 but the application was rejected by the company as there were no relief conductors available. On the next day, the employee proceeded with the job as usual. While loading the luggage, he vomited and later suffered a stroke. After the incidence, the whole of his left body became paralysed.

A claim was made towards the employer in June 1967 on the failure to ensure the safety and health of the employee by rejecting the leave application. The Federal Court rejected the claim on the ground that the plaintiff failed to prove that he made the application for leave on April 10. Even if an application was made and rejected by the employer, the stroke was not foreseeable as the consequences of the rejection. The employer's action was too remote to be attributed to the stroke. Hence, there was no relationship of cause and effect established between the respondents' failure to grant their employee leave of absence for the day and the stroke. The damage also was not foreseeable.

From this case, it is submitted that the worker not only has to prove the causation in fact that the disease is a consequence of his occupation, but also the injury is not too remote to relate with the occupation. Nevertheless, the court has permitted the compensation

\footnotetext{
18 According to section 4(5) Workmen's Compensation Ordinance 1952, an accident being in the course of employment is deemed to have arisen out of the employment until the contrary is proved.

$19 \quad[1970] 1$ MLJ 188
} 
under the Workmen's Compensation Ordinance 1952 because the death was presumed to have arisen out of the employment.

In conclusion, all the four cases above showed that the employer's liability in ensuring the workers' safety and health had been in issue even before the formation of ESSA 1969 and OSHA 1994. The issue of causation needs to be settled in order to have a successful claim. Hence, an employee must prove first that the injury can be attributed to the occupation and not to anything else. Nevertheless, any injury or disease which was not originated from work also can be claimed provided that the worker can show that it was aggravated by the occupation.

After the enforcement of ESSA 1969, a few cases involving injury in work place made on tort basis. This probably due to the compensation scheme which was introduced under the Act enabling most manual workers to claim compensation without the burden of proving the liability of employers. In addition, all workers in private sector must be insured by their employers under this scheme. Below, are among the claims that were made under tort basis.

In the case of Eastern Mining and Metals Co Sdn Bhd $\mathrm{v}$ Wan Absah Bt. Mohamed \& $\mathrm{Ors}^{20}$, One Long bin $\mathrm{Hj}$ Mohamed was employed as a rocker operator in the defendant's company. He died after complaining pain in his chest to his employer. His family-respondent made a claim for compensation to the Assistant Director of Workers' Affairs, Dungun and the employer was ordered to pay a sum $\$ 7,200$. An appeal was made by the employer against the order.

The High Court Kuala Terengganu rejected the appeal on the ground that although the death could be caused by several factors such as old age (50 years old), diabetes and hypertension, the work factor has aggravated the condition of the disease. The nature of the work was so tough and was carried for a long term i.e. 15 years. Hence, it aggravated his health condition and further, caused his death. Lord Atkin judge stated:

It appears to me that if it is established that a man suffers a strain of the heart which causes death as a result of the work engaged in, nobody can say that he has not

$20 \quad[1974] 2$ MLJ 210 
sustained a physiological injury, and, therefore, has met with an accidental injury.

He further added:

the nature of the work of the deceased as a rocker operator for the past 15 years and six days was the contributory cause of the hastening of his heart attack" and I therefore agree with the learned arbitrator's finding that "the deceased's death was due to an accident within the meaning and in the context of the Workmen Compensation Ordinance, even though it was not attributable to any sudden strain having been put on the deceased on the day in question.

In summation, it can be observed that the judgment given is liberal in nature. It means, even a disease is not originated from the occupation, compensation claim can still be made if a worker can prove the work-aggravated factor. Compensation will be awarded by the court on the basis of 'apportionment'. It means, the compensation awarded will not be in full, but apportioned accordingly depending on the contribution of the work.

The decision which considers the 'work-aggravated' factor is distinguished from the judgment in the case of Persin Kaur decided 7 years before. In the case of Persin Kaur, the work term i.e. 40 years was not considered at all by the court compared to the consideration given to the term of 15 years work in the case of Wan Absah. Furthermore, the workers in these two cases died due to the same reason i.e. heart attack and their age were not much different.

To conclude, the contrast judgment in these two cases explained that there is no single objective test to determine whether a worker's death is due to his occupation or not. It will depend on the facts of each particular case and how the claimant can prove the breach of liability by the employer.

While in the case of Ho Teck Fah v. Looi Wan T/A Looi Construction, ${ }^{21}$ a skilled carpenter employed by the defendant fell

[1981] 1 MLJ 162 
down and sustained serious injuries while engaged in fixing the roofing of a factory building. In consequence, he became paralysed waist downwards. The employee contended that the injury was due to the failure of the employer to provide a harness to prevent him from falling, a scaffolding to secure a firm hold or a net to break and render harmless his fall. ${ }^{22}$. The court decided that the employer was in breach of the duties and awarded compensation to the employee for the injuries and the future loss of earning.

Although this case is an accident case, the need to prove the liability of employer and the failure in performing the duty is still relevant in the discussion and the same goes to the case of disease. The case shows that, the standard of liability in accident cases is at par with the level in disease case. The employee must show that the liability and its failure or negligence in performing the duty which caused the injury.

Next, the case of Director General SOCSO v Philip bin Felix@ Philip bin Sintik ${ }^{23}$ and the case of Director General SOCSO v Nor Azian binti Adnan, ${ }^{24}$ involved accidents of employees during sports practice session that usually took place after office hours. The appellant held that the incidents were not cases of 'employment injury' within the meaning of s 2(6) of ESSA due to the fact that the accident that was sustained by the respondents while they were playing. In addition, it happened after office hours and it was not part of their job. The appeals were however dismissed by the High Court. The court was of the opinion that all actions done by the respondent were 'incidental to this contract of service although they might be under no duty to do it' and the injury sustained arose in the course of employment and were 'employment injury' and the injury sustained were attributed to the occupation.

The High Court in both cases highlighted that the interpretation of 'employment injury'under section 2(6) ESSA 1969 is not necessarily limited to injury or diseases occurred while performing the actual job only. The interpretation can be extended to any job which is done instructed by the employer and for benefit of the employer.

\footnotetext{
22 The duty was provided under section 10 Factories and Machinery Act 1967

23 [2004] 5 MLJ 251

$24 \quad$ [2004] 3 MLJ 193
} 
The case of Che Noh Bin Yaacob v. Syarikat Kilang Getah Seng Hin, ${ }^{25}$ High Court [Kota Bharu]. In this case, a tort claim was made by an employee who sustained injuries during work. The claim however, was rejected by the High Court on the ground that it contravened section 31 ESSA $1969^{26}$. It means, when a compensation claim has been made to SOCSO, another claim on the same injury or disease is barred.

In the case of Umang AK Antam v. Director General, SOCSO ${ }^{27}$, the appellant applied for the benefit on his son's death as a painter at the respondent's company. Since the death occurred during work, it is presumed that it arose out of and in the course of employment. SOCSO then failed to prove the contrary (e.g. by presenting expert evidence stating otherwise), and compensation was awarded successfully to the beneficiaries.

From the case above, it can be concluded that it is important for a claimant to establish that the death or disease occur in the course of employment. Next, it will be the duty of the defendant to prove that the disease is 'not occupational'. Here, the defendant can rebut the presumption provided under section 23 of the ESSA $1969^{28}$, by giving scientific evidence as done in the case of Persin Kaur.

There is a Singaporean case where the issue of causation can be analysed. In the case of Chew Swee Hiang v Attorney General of Singapore \& Anor, ${ }^{29}$ High Court [Singapore], the service of the plaintiff, a teacher in a school, was terminated. The reason was, she was considered not fit to continue the profession due to her disease i.e. spondylosis (musculoskeletal pain from the neck towards hand). After undergoing through an operation, she found some difficulty in speaking and swallowing food and water.

She made a claim against the Attorney General of Singapore as the first defendant and the doctor in charge of the operation as the

[1980] 2 MLJ 264

26 Section 31 of the ESSA 1969 provides that claims for personal injury on other basis cannot be made after claim to SOCSO has been instituted.

27 [1999] 1 CLJ 433

28 Section 23 of the ESSA 1969 provides that any accident will be deemed arose from and in the course of employment.

29 [1991] 1 MLJ 284 
second defendant due to his negligence in carrying out the operation successfully. The negligence caused her to suffer the disease and as a result, she was terminated from the service. Among the issues in question are whether the disease suffered was occupational because she had to bend her head to mark the papers of her pupils. As a result, the bone in her neck was pressed against the nerve. The High Court in its judgment dismissed the plaintiff's claim. The plaintiff was held failed to establish that the disease was due to her work factor or the surgery. A number different factors could cause the injury and there can be presumption that one factor caused the injury rather than the others. In addition, the loss of voice first occurred two months after the operation.

It can be observed from this case that if a number of different factors could cause the disease, the claimant has to show that the work contributed materially to the disease or the sole cause of it. A presumption that the work factor prevail rather than the other factors will not be made by the court.

\section{Conclusion}

In conclusion, the task in proving the relation between disease and work is not easy. The determination whether a disease is 'occupational' is very subjective and there are many other factors would come into consideration. However, in spite of this hardship, some cases show that a claim for diseases which are not originated from work can still made if the worker can show that the work factor has aggravated the disease materially. In other words, the interpretation of the phrase 'occupational disease' is liberal and no specific standard in use to determine the causation.

From the case analysis, it also can be observed that many claims were turned down due to the failure to establish a strong relation between 'disease' and 'occupation'. The statistics on disease claims to SOCSO also is very few compared to the occupational hazards faced by the workers. In this respect also, the disease claims sound inconsiderate with the increase in the number of workers and the rise of the relating sectors. A need to provide occupational health services can be proposed help the work people. Providing a scheduled medical monitoring for example, will detect any disease 
at the early stage and this further helps workers in diagnosing their disease. Hence, the relationship between occupation and disease can be established through the medical evidence.

\section{References}

$15^{\text {th }}$ Asian Conference on Occupational Health Proceedings 1997, 6-8 June Istana Hotel, Kuala Lumpur.

Dept. of Occupational Health and Safety (DOSH), Ministry of Human Resource.

El Batawi, M.A., Schilling, RSF, and Valic F., Byssinosis in the Egyptian cotton industry; changes in ventilatory capacity during the day, 1964, Br. J. Ind. Med., 21.

Jeyaratnam, J., Occupational Health in Developing Countries, 1992, Oxford University Press, New York.

Koh, Kee Seng \& Jeyaratnam, Occupational Medicine Practice, $2^{\text {nd }}$ ed. Singapore: World Scientific Publishing Co. Pte. Ltd, 2001).

SOCSO Annual Report 2001 - 2006.

WHO (World Health Organisation). Report of a WHO Expert Committee on Environmental and Health Monitoring in Occupational Health, 1973, WHO Technical Report Series, No.535, WHO, Geneva. 